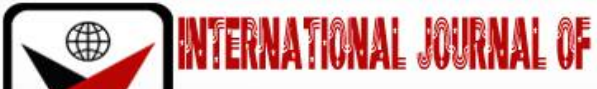

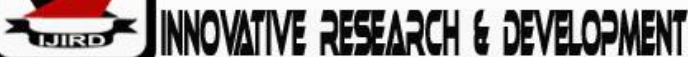

ISSN 2278-0211 (Online)

\section{Assisting Pupils to Solve Linear Equations Involving the Variable}

\author{
Dennis Offei Kwakye \\ Tutor, Department of Mathematics and ICT, Enchi College of Education, Enchi, Ghana
}

\begin{abstract}
:
This study was to assist pupils of Asafoakye M/A J.H.S one in the Enchi District of the Western North Region in Ghana to use the Flag Diagram, Least Common Multiple and the Balancing Method to solve Linear Equations Involving one variable. The pupils were 36 in the class and a sample size of 30 was selected using the purposive sampling technique. These pupils were selected after a pre-intervention test was conducted and 30 pupils who performed abysmally were used for the project. The research sought to find answers to two research questions: What is the level of pupils' knowledge in solving Linear Equation involving on variable? To what extent can pupils solve Linear Equations involving one variable using the Flag diagram, the Least Common Multiple method and the Balancing method after the intervention? The instruments used in collecting the data were test and observation. The research design adopted by the researcher was an action research which involved pre-intervention, intervention and post - intervention. One of the major findings discovered was that pupils can confidently use Flag Diagram, Least Common Multiple Method and the Balancing Method to solve any kind of Linear Equations involving one variable. The recommendation put forward by the researcher was the use of different approaches and varied models and methods should be adopted by teachers in the teaching and learning of mathematics especially at the Basic School Level.
\end{abstract}

Keywords: Flag diagram, least common multiple, balancing method, linear equations, models

\section{Introduction}

\subsection{Background to the Study}

Development in almost all areas of life is based on the knowledge of Mathematics. As a country, there cannot be meaningful development in virtually any area of life without the human resource base having vast knowledge in the concept of Mathematics. It is for this reason that the education system of countries that are concerned about their development put great deal of emphasis on the study of Mathematics.

Mathematics is one of the essential subjects which are needed in everyday life. It is one of the pre-requisite subjects needed by man in many subject areas. Meanwhile, many people on the other hand find it difficult to cope with it. This is due to the fact that most teachers who handle the subject do not use the right technique in teaching the subject.

This situation scares most pupils and do not want to hear the name 'Mathematics'. Most teachers also haphazardly teach the subject since they themselves do not have the requisite skills. Also, more knowledgeable teachers sometimes overestimate the accessibility of symbols-bases representations and procedures (Nathan \&Kiesinger, 2000).

Most of the pupils perceive Mathematics to be a difficult subject which seems to be a misconception. Mathematics is not a difficult subject at all but the ability to solve Mathematics problems sometimes depend on the background of pupils and the way they view education.

The numerous benefits of studying Linear Equations include: it could be applied in the fields of Engineering, Accountancy, Medicine and other equally important avenues like Marketing. It is also used in everyday life and helps in Logical Reasoning. Linear Equations involving one or more variables are one of the many topics in Mathematics that has gotten a wide area of applications.

In this research, the researcher too looked at simple Linear Equations in one variable. That means there will be no $x^{2}$ terms, no $x^{3}$ 's just $x$ terms and numbers. For example, we will see how to solve the equation $3 x+15=x+25$ using the Flag Diagram, the Least Common Multiple (LCM) method and the Balancing Method.

The important thing to remember about Linear Equations is that, the 'equal sign' represents a 'balance'. What an 'equal sign' says is that, 'what is on the left-hand side is exactly the same as what is on the right-hand side'. In any Linear Equation, there is an unknown quantity say $x$, which is what we try to find. Linear Equations in one variable occurs so frequently in the solution of other problems like Word Problem (Story Problems) where the whole story is reduced to a Linear Equation to make the solving very simple.

Thus, a thorough understanding of Linear Equations in one variable is very essential in the world of Mathematics. 


\subsection{Statement of the Problem}

The first topic the researcher treated with the pupils during internship period at Asafoakye M/A JHS was 'Linear Equations in one variable', a topic in the Mathematics syllabus. In the course of the teaching, all the pupils were nodding their heads and contributing immensely to signify that some of the students were neither contributing to the lesson nor nodding their heads. They seemed to be totally confused and did not know what to do and even produced wrong answers whenever a question was directed to them.

After teaching the topic, exercises were given to the class and pupils performed poorly although some few pupils in the class excelled as they have been introduced to the same topic in the First Term of the Academic year.

\subsection{Purpose of the Study}

The purpose of the study was to identify the level of pupil's knowledge of solving Linear Equations involving one variable and also, to assess the understanding in teaching the Linear Equations in one variable when using the Flag Diagram, Least Common Multiple method and Balancing Method.

\subsection{Research Questions}

The following questions guide this research work:

- What us the level of pupil's knowledge in solving Linear Equations involving one variable?

- To what extent can pupils solve Linear Equations involving one variable using the Flag Diagram, the Least Common Multiple method and the Balancing method after the intervention?

\subsection{Significance of the Study}

It is hoped that the findings will draw the attention of the Ministry of Education, Ghana Education Service and other stakeholders to find possible ways of addressing the problem.

This study will serve as literature review for further studies and research.

It will also spell the effective teaching and learning methods to be used by Mathematics Teachers as well as the various diagrams and illustrations appropriate for the topic. Teachers, researchers and pupils can use it as a reference material.

\subsection{Limitations of the Study}

The researcher work was conducted for JHS One Pupils of Asafoakye M/A JHS, taking cognizance of the time and cost involved when taken on a wide scale. The choice of the sort of teaching technique to motivate pupils to get involved in the activities carried on in the research was a challenge limiting the research to a few teaching methods.

\subsection{Delimitations of the Study}

The study focused on JHS One Pupils of Asafoakye M/A JHS and Linear Equations involving one variable. There are many ways of solving Linear Equations involving one variable but the study centered on the use of Flag Diagrams, Least Common Multiples (LCM) and the Balancing method.

\subsection{Organization of the Study}

The study was organized into five chapters. The chapter one dealt with the introduction. It included the background, statement of problem, purpose of the study, research questions, and significance of the study, limitations, delimitations and organization of the study. The chapter two was the review of related literature. It consisted of overview, the importance of Mathematics, Linear Equations involving one variable, causes of pupils' inability to solve Linear Equations, strategies to be used to overcome pupils' inability to solve Linear Equations in one variable. The chapter three dealt with the methodology. This included the research design, population, sampling procedure, research instruments, pre-intervention, intervention, post-intervention and data analysis. The chapter four threw light on the result and discussion findings. The last chapter was chapter five which dealt with summary, conclusions and recommendations.

\section{Review of Related Literature}

\subsection{Overview}

This chapter dealt with the review of related literature of scholars and other people who have said something about the topic under study. It is then very crucial at this stage for the research to review some of the books, magazines and other writings of these scholars in line with the research topic.

\subsection{Mathematics and Some Importance}

The effectiveness of what is learnt lies in its application and the main objective of whatever is learnt in school is that it would be employed in future either in other school situation or in real life situation. Martin (1994) backed this by saying that Mathematics helps to develop logical thinking.

Appau (1994) writing on the importance of Mathematics stated that, the place of Mathematics in everyday life of the individual and communities cannot be over emphasized. In commerce and Industry, Mathematics is used extensively to maximize production and profits. In the home, Mathematics play a unique role in managing the family resources.

Mathematics is applied in all human endeavors for better results. According to Appau (1994), mathematics provides a powerful means to communicate, explain and predict. The point here is that, through the manipulation of 
figures, making use of the underlining concepts one made clear and the making of prediction is also made possible through the study of figures and how to manipulate variables.

following:

According to Nughes (1981), the importance of Mathematics in the school curriculum has been justified in the

- To be able to count and make simple calculation with numbers.

- To be able to recognize shapes and some of their properties.

- To be able to use variables to represent the unknown.

- To be able to know about money and be able to make simple calculations.

- Mathematics is used in finding answers to questions and problems which arises in our everyday life.

- In the modern world, Mathematics is being increasingly used in Science, Technology, Industry, Governance, Education and Economics.

Lowry (1992) stated that, 'learning Mathematics is the means of developing logical and quantitative thinking abilities. Mathematics becomes functional in the lives of children when they develop basic computational skills and can apply Mathematics to their world' (p. 95). The approach to the teaching and learning of Mathematics is accepted by some school educators and instructors that teaching and learning are processes through which the child passes to obtain certain behaviours through personal experience and it is the work of the teacher to facilitate this process.Skemp(1971) contributed to his view by arguing out the approach to teaching of Mathematics in the classroom must be rooted in two coherent objectives which are:

- The need to pass on to the child Mathematical facts and techniques:

- The need to facilitate the development of each pupil's ability to think for himself or herself in acquiring and applying his or her knowledge.

Martin (1994) writing on Mathematics for Teacher Training Colleges remarked that teachers should aim at making their teaching lively and enjoyable. He continued by saying that this can be realized if each child feels personally involved in.

\subsection{Linear Equations}

Many problems in Engineering and Finance reduce to the solution of an equation or set of equations. An equation is a type of Mathematical expression which contains one or more unknown quantities which is required to be found.

Linear Equations are equations which contains single or more unknown quantities. Thus, if $a, b$ and $r$ are real numbers and if $a$ and $b$ are not both equal to 0 then, $a x+b y=r$ is called a Linear Equation in two variables: the two variables are $x$ and $y$. The real numbers $a$ and $b$ are called the coefficients of the equation $a x+b y=r$. The number $r$ is called the constant of the equation. Examples: $\quad 10 x-3 y=5$ and $-2 x-4 y=4$ are Linear Equations involving two variables. We can have Linear Equations involving three or more variables, but this project is limited to Linear Equations involving one variable.

\subsection{Linear Equations Involving One Variable}

Linear Equations involving one variable is an equation of the form $a x+b=0, a \neq 0$ where $a$ and $b$ are known numbers and $x$ represents an unknown quantity which we must find. In the equation $a x+b=0$, the number $a$ is called the coefficient of $x$, and the number $b$ is called the constant term. The following are examples of Linear Equations in one variable: $3 x+4=0,-2 x+3=0, \quad-\frac{1}{2} x-3=10$. The unknown $x$ appears only to the first power, that is, $x$ and not as $x^{2}, \sqrt{x}$ or $x^{\frac{1}{2}}$.

Different letters are sometimes used for the unknown quantity. For example, $2 x=x+1,3 t-7=17,13=3 n+$ 1 and $1-\frac{1}{3} y=3$. Some of the methods used to solve Linear Equations in one variable are the Flag Diagram, Least Common Multiple and the Balancing method which will be dealt with in the next chapter. To solve a Linear Equation, we try to make the unknown quantity the subject of the equation. This means we attempt to obtain the unknown quantity to be on its own on the left-hand side of the equal sign. We can then check our solution by substituting the answer for the unknown quantity into the equation to see if both sides of the equation using the 'equal sign' at the middle are equal.

\subsection{Causes of Pupils Inability to Solve Linear Equations Involving One Variable}

According to Karl (1999, p. 79), 'Mathematics is a very interesting and straight forward way of solving problems in life and hence the Linear Equations in one variable under the broad spectrum of Algebra'. He noted that, although Linear

Equations are very easy to work, one can have interest in it if only the environment and the atmosphere or the home in which the pupils live is very conducive for learning.

The problem is farther compounded by teachers of Mathematics who are not able to explain the various methods and approaches in dealing with the topic, 'Linear Equations involving one variable'.

The researcher also discouraged the rote or instrumental way of teaching Mathematics since it is a major factor of the increase in the problems of children learning Mathematics. The beginning of building new Mathematics ideas or facts should involve some practical activities and discoveries by each child drawing, sorting, classifying, measuring, investigating and with simple clear questions to answer. Children can clearly think for themselves if they understand such practical activities, if they are allowed to ask questions and get involved in discussions among themselves.

Karl (1999) again said, 'aside the background of the pupil, the use of appropriate teaching method and correct activity to teach the topic can also help pupils to effectively solve problems on the topic. Teachers' inability to arrange the 
topic chronologically also affects pupils' inability to understand the various topics. This is because, certain topics are better understood if they follow another topic which gives the child pre-knowledge of that topic (Etsey, 2006).

\subsection{Strategies to Be Used to Overcome the Pupils' Inability to Solve Linear Equations in One Variable}

According to Martin (2002), when pupils have lived in a conducive environment, following steps can help them solve problems involving Linear Equations in one variable. The steps below can be followed to explain Linear Equations to pupils understanding.

\subsubsection{The Balancing Method}

- Multiply both sides of the equation by the least multiple of any denominator to clear the equation of fractions.

- Remove any grouping symbols by applying the distributive property.

- Combine any like terms on either side of the combination.

- Apply the addition property of equality to write an equivalent equation with the variable isolated on one side of the equation.

- Apply the multiplication property of equality to write an equivalent equation with the variable term isolated on one side of the equation.

- Check the solution in the original equation. Note, if the equation derived in step 'e' is always true, then the answer is gotten. If the equation is false, then there is a contradiction.

\subsubsection{Least Common Multiple (LCM) Method}

From the book of Alfred and Mendal Mathematics for Basic Schools (2005), following these steps can help pupils to effectively solve problems on Linear Equations in one variable.

- Clear fractions by multiplying both sides by the highest LCM.

- Use distributive property to remove parenthesis (brackets) by expanding the terms in the brackets.

- Simplify each side by combining like terms.

- Use the addition property to collect all variable terms on one side of the equation and all constant terms on the other side.

- Use multiplication property to write the variable term with the coefficient of 1.

- Check the solution in the original equation.

Again, from Dolciani, Kelvin and Martial (2003), it should be noted that for a given Linear Equations in one variable, what is done to one side of the equation should also be done on the other side to keep the equation balanced. Whenever a number is being taken from one side of the equation to the other side, first thing to look out is the variable assigned to it. Having done that, apply the same variable with an opposite notation to it and do the same to the other side of the equation. They further concluded that if the mathematical operation at the final stage of the solution is subtraction $(-)$, apply addition $(+)$. If the operation is multiplication $(\times)$, apply division $(\div)$ sign.

\section{Methodology}

This chapter caters for the research design, population, sample and sampling procedure, research instruments, pre-intervention, intervention, post-intervention, data collection procedure and the method used to analyze the data.

\subsection{Research Design}

The research design adopted by the researcher is action research. Action research according to Atiku (2005) is a research which is conducted with the purpose of solving classroom or local problems through the application of scientific methods. Carr \&Kemmis (1978), put their general definition of action research into education setting as 'a research is a form of self-reflective inquiry that can be utilized by teachers in order to improve the rationality and justice of:

- Their own practices

- Their understanding of these practices and

- The situation in which these practices are carried out.

Obviously, the role of action research in education has been acknowledged for a long time when Hutchinson, Whitehouse and Lomax (2007) claimed that action research is a research that concerns with broader curriculum issues, and often with the administration and management of school and institutional change. Glickman (2009) says that action research in educational setting is a study conducted by teacher researchers to improve problem solving in their classrooms.

In addition, Calhoun (2010 p.10) explains action research as a fancy research when she says that 'let us study what is happening in our school and decide how to make it a better place'.

In short, it is possible to say that action research can be looked at as a professional development tool since it tries to enhance the capacity of teachers as generator of professional knowledge in contrast to enhancing their capacity to apply someone else's knowledge, (Burns, 2011). Action research is actually suitable for any person who wishes to improve his or her performance or any group of organization who hopes for doing the same.

As a matter of fact, action research is widely used in education, especially by teachers who use it to improve their teaching although it has got some shortfalls. Action research is costly, time consuming and stressful to undertake since it 
involves a lot of activities such as planning or designing, implementation and evaluation, just to

mention a few. It can also tend to be biased if personal feelings and sentiments are not well controlled.

\subsection{Population}

The researcher's population was pupils of Asafoakye M/A Junior High School and the target population was pupils of Basic Stage Seven to which the researcher ultimately wants to generalize the results. The target population was made up or 36 pupils with 20 being boys and 16 girls.

\subsection{Sample and Sampling Procedure}

Sample in research activities is the subset of population. Purposive sampling was used to select 36 pupils from the population. The number of boys was 20 and the rest being girls. Their average age was 14 . In order to get the sample size, a test was conducted on the topic Linear 'Equations in one variable'. Out of the population of 36, 16 pupils scored above the average mark of 5 out of 10 test items. These 16 pupils were excluded from the research and so 20 pupils who scored low marks were used for the research.

\subsection{Research Instruments}

The research instruments used in collecting the data were test and observation.

\subsection{Data Collection Procedure}

Data were collected using the research instrument stated.

\subsection{Observation}

Observation was one method by which data was collected for the study. Thus, the researcher did at different stages of the study which included Pre-Intervention, during the Intervention stage and the Post-Intervention stage.

The purpose of the observation instrument was in three folds. At the Pre- Intervention stage, it helped the researcher at first hand to determine the pupil's problems or difficulties. It also helped the researcher at the Intervention stage to find out how the pupils apply the explanations and illustrations at their disposal.

Furthermore, it was at the Post-Intervention stage that observation helped to find out whether the intervention technique had any influence on the pupil's approach to solving Linear Equations. Also, Class Tests and Class Exercises were other ways by which data were collected for the study. Through observation, the researcher identified that pupils had problems with finding LCM and regrouping like terms which was used as evidence that helped to determine the actual difficulty and problems of pupils.

Finally, during the observation, the test and exercises conducted at the Post-Intervention stage of the study helped the researcher to find out how effective the intervention had been; the level of success of the intervention strategies and also whether certain level of difficulty still persisted.

\subsection{Intervention Design and Implementation}

\subsubsection{Pre-Intervention}

The Pre-Intervention was collected at the start of the study at the school of research. The test consisted of 10 questions and pupils were allowed to use any method to solve the questions. The pupils' performance in the test brought out their inability to deal with problems on Linear Equations which is a major component of Algebra.

\subsubsection{Intervention}

The Intervention of the research involves implementation, teaching and learning task. The researcher used illustrations and explanation of the various methods in which Linear Equations involving one variable could be used in solving and they included Flag Diagram, the Balancing Method and the Least Common Multiple method.

\subsubsection{Implementation}

The research intervened through series of lessons on the topic 'Linear Equations' for 2 hours a day, for three days in two weeks. That amounted to twelve (12) hours contact hours (periods) in all. Pupils were engaged in variety of activities using the Flag Diagram method. To buttress whatever was written earlier and to help pupils to become more conversant with the concept, the researcher introduced and demonstrated the Flag Diagram and the various questions which are suitable to use. They were also taken through finding Least Common Multiple method and the Balancing methods of solving Linear Equations.

\subsubsection{Teaching and Learning Tasks}

\subsubsection{Activity 1}

3.7.4.1.1. Solving Linear Equations Involving One Variable with the Flag Diagram

The researcher's intervention strategies were in the form of concrete approach, activities and discussions with the relevant instructional materials.

Example: $2 x+3=9$, usingFlag Diagram for the equation $2 x+3=9$ is given as follows: 


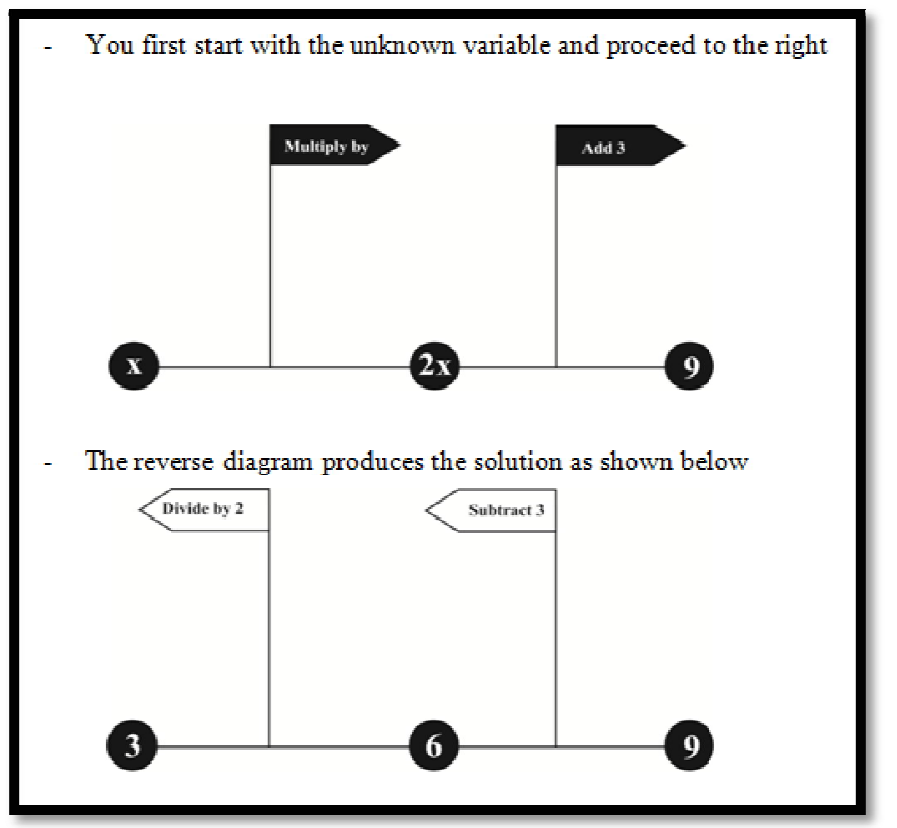

Figure 1

$\therefore, 2 x+3=9, \rightarrow x=3$.

\subsubsection{Activity 2}

\subsection{Solving Linear Equations in One Variable Using the Balancing Method}

When solving an equation, you want all the 'letter terms' on one side of the equal sign and 'all numbers' on the other side.

NOTE: Letter means $=$ number terms

To obtain this by the Balancing Method:

- Add the same quantity to each other

- Subtract the same quantity from each side

- Multiply each side by the same quantity

- Divide each side by the same quantity

We do the above to get rid of some unwanted terms from each side of the equation. To get rid of a term, subtract the term from each side. Also, to get rid of a '- term', add the term to each side.

Example of an illustration of the Balancing Method to solve $5 x-3=3 x+7$

STEPS

To get rid of $3 x$, subtract $3 x$ from both sides, i.e.

i.e. $5 x-3-3 x=3 x+7-3 x$

$2 x-3=7$

Next, to get rid of -3 , add 3 to both sides

i.e. $2 x-3+3=7+3$

NOTE:

$$
2 x=10
$$

Now, when solving an equation, the letter should stand on its own.

Therefore, dividing both sides by 2 gives;

$$
\frac{2 x}{2}=\frac{10}{2}, x=5
$$

\subsubsection{Activity 3}

\subsection{Using the LCM Method to Solve Linear Equations in One Variable}

The general steps explained to pupils for solving Linear Equations at their stage are as follows:

Check if there are fractions. If there are fractions, multiply both sides of the equation by the LCM of the denominators to clear the fractions.

$$
\text { Example: Find } x \text { if } \frac{1}{x}+\frac{1}{3}=1
$$

Solution

$$
\frac{1}{x}+\frac{1}{3}=1
$$

Multiply through by $3 x$ (i.e. the LCM of $x$ and 3)

$$
3+x=3 x \text { (Grouping like terms) }
$$




$$
\begin{aligned}
& 2 x=3 \text { (Divide both sides by } 2 \text { ) } \\
& x=11_{2}^{1}
\end{aligned}
$$

Therefore, further class exercise and group work, pupils were able to solve samples of questions on Linear Equations using various methods before the Post-Test exercise was administered to pupils.

\subsection{Post-Intervention}

The researcher used observation and test to collect data for the problem. The researcher observed pupils during Mathematics lesson and also saw that the pupils were finding it very difficult to solve Linear Equations involving one variable during instructional hours.

The researcher again selected some simple Linear Equations question involving one variable from Pupils Mathematics textbooks to determine the extent of problem. The researcher also used a written and oral test as the PreTest items for the study.

The researcher used the Flag Diagram, Balancing method and the Least Common Multiple methods as some intervention strategies to minimize their problem.

\subsection{Data Analysis}

The researcher used tables, chart, figures and percentage to analyze the data of the study.

\section{Discussion of Results and Findings}

\subsection{Overview}

This chapter presented data gathered in table from the scores obtained by pupils on the Pre-Intervention test and Post-Intervention test administered to therm. The data collected have been analyzed based on the research questions. This chapter also deals with the discussions of the findings.

Pre-Intervention test was conducted to find out the level of acknowledge of pupils in solving Linear Equations involving one variable.

\begin{tabular}{|c|c|c|}
\hline Scores & Number of Pupils & Percentage (\%) \\
\hline $0-2$ & 18 & 60 \\
\hline $3-5$ & 12 & 40 \\
\hline $6-8$ & 0 & 0 \\
\hline $9-10$ & 0 & 0 \\
\hline Total & 30 & 100 \\
\hline
\end{tabular}

The data is presented in Table 1

Table 1: Pre-Intervention Test Scores

From Table 1, the minimum range of score was $0-2$ and it was scored by 18 pupils with a percentage of 60 . Within this range, 13 pupils scored zero mark. The highest range of score was $3-5$ with five pupils scoring half the mark out of the total score of 10. Nobody had a score above 5. Analyzing further from the Pre-Test exercise, all the 30 pupils have problem in regrouping and clearing fractions as they lack the correct understanding of the 'equal sign' with regards to solving Linear Equations in one variable.

During the Pre-Test, all pupils attempted the 10 test items. From all that have been reviewed above, one could agree with Caglayan and Olive 2010 that students experience difficulty in the correct understanding of the 'equal sign' as a symbol of 'equality'.

'Equal sign' is of utmost importance as students learn to solve Linear Equations at an early stage.

Evaluation analysis was done through the Post-Intervention test score as shown on the table below.

\begin{tabular}{|c|c|c|}
\hline Scores & Number of Pupils & Percentage (\%) \\
\hline $0-2$ & 0 & 0 \\
\hline $3-5$ & 4 & 13.33 \\
\hline $6-8$ & 19 & 63.33 \\
\hline $9-10$ & 7 & 23.34 \\
\hline Total & 30 & 100 \\
\hline
\end{tabular}

Table 2: Post-Intervention Test Scores

From the table, four pupils had the minimum score of $3-5$ marks out of 10 marks with a percentage frequency of $13.33 \%$. Seven pupils scored $9-10$ marks out of 10 test items with a frequency of 7 and $23.34 \%$. Nineteen pupils had a score within the range $6-8$ with a percentage frequency of $63.33 \%$.

The difference between the Pre-Test and the Post-Test could make one agree with Martin (1994) who said on mathematics for Teacher Training Colleges that 'teachers should make teaching lively and enjoyable. He continued by saying that this can be released if each child feels personally involved and understands the work, he or she is involved in. It can also be seen that the intervention put in place yelled a positive outcome as pupils who scored zero in the Pre-Test had a mark above the class average in the Post-Test exercise. 


\section{Discussion}

The Post-Intervention test result from the analysis indicated that the pupils performed better in the Post-Test exercise than the Pre-Intervention Test. In case of the sign score in the Post-Test, the pupil's performance showed a sort of improvement.

From the discussion of the data represented on the Table 1 and 2, if pupils have had enough time to practice on how Linear Equations were, they have been assisted, supervised and motivated in Linear Equations and mathematics would become easier and more understandable.

There has been a clear indication from the results obtained that Linear Equations involving one variable through demonstrations, practical activities, games and motivation for beginners is the best and most convenient approach. Thus, through the various activities like the use of Least Common Multiple, Flag Diagram method and the Balancing Method.

Again, the results from all the evaluation exercise clearly showed that the activity designed for this study have the differences of performance as in the Pre-Test of pupils scored lowest, below average and above average marks is an indication of improvement as in Post-Test. The performance of the pupils can now be inferred that vast difference of their performance in the Post-Test was brought about as a result of the intervention strategies employed by the researcher.

\section{Summary, Conclusions and Recommendation}

\subsection{Overview}

This chapter caters for the summary and conclusions of the study. It also deals with the recommendations of the study. It also deals with the recommendations of the study based on the findings.

\subsection{Summary of Findings}

The Pre-Intervention test conducted disclosed the pupils don't have much knowledge in the Flag Diagram, Least Common Multiple and the Balancing method of solving Linear Equations in one variable. It was also found that pupils lacked the skills on fractions, Least Common Multiple and regrouping. The analysis of the Post-Intervention test shows the pupils performed better after the well-planned interventions. This implies that when teaching and learning, illustration employed, pupils performed better.

\subsection{Conclusions}

From the analysis of the data the researcher collected, it came out that pupils' lack basic knowledge in Linear Equations such as how to find Least Common Multiples and dealing with Equations involving fractions. Also, pupils were introduced to only one method of solving Linear Equations which they did not even understand very well.

It was also clear that the pupils were not at all lazy and dull as they were branded by their teachers; rather the problem was the recognition and use of teaching and learning illustrations which most basic school do not appreciate and see them as waste of time and energy. The pupils will perform better when they are introduced to variety of teaching and learning materials during the treatment period. This will help them in their understanding of the concept and this reflected in the Post - Intervention test results.

\subsection{Recommendations}

On the basis of the findings, the following recommendations are made to improve teaching and learning of mathematics in Ghanaian schools and more importantly Asafoakye M/A J.H.S;

- Different approaches and use of varied models and methods should be adopted by teachers in the teaching and learning of mathematics especially at the basic level.

- The ministry of Education and the Ghana Education Service must sure that adequate teaching and learning materials are provided to every school no matter where it is situated and monitors the progress of both teachers and pupils regularly.

- $\quad$ Parents and guardians must be encouraged to show interest in the school and education of their wards.

\section{References}

i. Alfred, H. \& Mendah, A. K. (2005). Mathematics for basic schools. Accra: New Press Publishers.

ii. Atiku, (2006). Mathematics for Teacher Training College. Accra: Unimax Publisher.

iii. Appau, (1994). Mathematical Principles. Accra: Repro Press Ltd.

iv. Carr \& Kem, (1978). Modern Mathematics 5 - 7. London: Pitman Press.

v. Calhoun, (2010). Foundation in Mathematics. London: Chapman and Hall.

vi. Caslayam and Olive (2010). Mathematics for Junior Secondary Schools.

vii. Dolciani, Kelvin, \& Martial, (2003). Guiding children's learning of Mathematics (5th ed.). California: Wadsworth Publishing Company.

viii. Etsey, (2004). Fundamentals of Mathematics. London: Macmillan Publishing Company.

ix. Glickman, B. K. (2009). Mathematics for Junior Secondary Schools, London: Macmillan Edu. Ltd.

X. Ghana Education Service (G. E. S.) (2007). Teaching syllabus for Mathematics (JHS 1 - 3). Accra: Sedco Publication. Hutchinson, Whitehouse \& Lomax, (2007). Algebra 2 and Trigonometry. London: Pitman Press.

xi. Karl, J. S. (1999). The Nature of Mathematics (7th ed.). New York: Brown Company Publishers. 
xii. Lowry D. W. (1992). Heat pre - Algebra. Illinois D. C: Heat Company Ltd.

xiii. Martin, J. L. (2002). Mathematics for Teacher Training Colleges in Ghana. Accra: Unimax Publisher.

xiv. Nathan \& Koedinger, (2001). Elementary school Mathematics methods and materials (4thed.).Dubuque: Brown company Publishers.

xv. Nughes, J. W. (1981). Developing Mathematics (2nd ed.). California: Wadsworth Publishing Company.

xvi. Skemp, R. R. (1971). Mathematics in the Primary Schools. London: Routledge Company. 